\title{
The Connotation and Development Path of SPOC-based Blended Course Adapted to "Internet + Vocational Education"
}

\author{
Bin $\mathrm{Xie}^{1, *}$ and Yingfeng Deng ${ }^{2}$ \\ ${ }^{1}$ Office of Academic Affairs, Dongguan Polytechnic, Dongguan, Guangdong 523808, China \\ ${ }^{2}$ College of Commerce, Dongguan Polytechnic, Dongguan, Guangdong 523808, China \\ *Corresponding author. Email: atxbin@dgpt.edu.cn
}

\begin{abstract} resources and the concept of iterative development.

\section{INTRODUCTION}

Vocational education courses should adapt to the characteristics of the "Internet + vocational education", integrate innovate with information technology innovatively, and meet students' diverse learning needs. The emergency teaching strategies based on live classes, online-courses and blended courses during the epidemic of COVID-19 fully demonstrate the importance of onlinecourses in the current education ecosystem. Online-courses and platforms provide resources, platforms and technical support for online and offline teaching, ensuring the normal operation of teaching during the epidemic of COVID-19. Online blended courses which are well-made and with reasonable design are the premise and core of high-quality online teaching.
\end{abstract}

To adapt to the demand of "Internet + vocational education", and improve teaching with modern information technology are the trend of current vocational education development. The necessity of blended course development and the theory are mainly analyzed. And a blended course development path model suitable for vocational education is constructed based on Conole's \& Buch's course development model. The model includes five stages such as team construction, analysis and modeling, course content reconstruction, integration and design, teaching and learning, and iteration, which also integrates dynamic generative

Keywords: Internet + Vocational Education; SPOC; Blended Course; Connotation and Path

\section{THE CONNOTATION OF BLENDED COURSES}

The concept of blended teaching is similar to blended learning[1], which refers to the combination of the face-toface teaching and the online learning, and combine the advantages of traditional teaching methods with the advantages of network teaching. Blended teaching not only plays the leading role of teachers, but also fully reflects the enthusiasm, initiative and creativity of students. Combined with traditional teaching methods, blended teaching can improve the teaching and learning effect in fragmented time, promote the systematization of learners' knowledge and skills training, and improve students' learning effect.
Blended teaching, combining MOOC/SPOC with classroom teaching, demonstrates the strong vitality in innovating teaching process, improving learning participation, promoting the deep learning, and also provides models of teaching from a collective education model to the innovative education model for colleges, which is also the respond to the colleges' demands in the Internet era.[2] Blended course is the new course form with the development of teaching methods in the background of "Internet +", and the integration and reconstruction of advantages of traditional course and online-course, which can not only support technology-based diversification of face-to-face teaching, but also integrate the online learning with the whole process of monitoring and real-time feedback, to form the new education ecology based on "Internet + " with supporting the dynamic changes of the curriculum system structure and knowledge content and the dynamic implement of course.

\section{THE PRACTICAL NEEDS OF "INTERNET + VOCATIONAL EDUCATION"}

\subsection{The inevitable requirements of innovation development of education and information technology in the new era}

The Action Plan of Education Informatization 2.0 points out that the integration of education and information technology should be transformed to innovative development and build a new mode of talent training under 
the condition of "Internet + ".[3] Schools and Teachers should make teaching changes according to the characteristics of students, change the curriculum structure, update the teaching concept, upgrade the teaching content, and innovate the teaching mode, to connect with the production practice and work process accurately in the new era of "Internet+". Through the blended teaching reform, schools and teachers should extend the traditional classroom teaching to the practice in production, service and work, and transform the single face-to-face teaching to online teaching and mobile learning to meet the new requirements of the development of teaching innovation mode under the "Internet + vocational education".

\subsection{The basis of the "DOUBLE CORES DOUBLE HELIX, TWO-WAY DOUBLE SUBJECTS" talent training mode}

Faced the new technology, model, formats, industrial transformation and upgrading, the talent training mode which means the spiral rise of core quality and core skills and the double main education body (school and enterprises), is the effective path of the cultivation of Highquality technical and skilled talents, and can promote students, teachers, schools, enterprises and other elements evolve in the ecosystem of the integration of education with industry.[4]Therefore, The vocational education both requires course content to integrate and reconstruct around the core skills and core quality and turn to work-processbased "online + offline" blended teaching from the traditional face-to-face teaching based on the characteristics of double learning environment(schools and enterprises),to deepen the integration of production and education and improve the quality of talents training.

\subsection{Practical challenges of teaching in higher vocational colleges under the background of millions of enrollment expansion}

Millions of enrollment expansion makes the inadequate teaching staff, teaching resources and teaching conditions in higher vocational colleges scarcer. It is very critical to innovate the "school + enterprise + online" three classroom teaching mode, and reconstruct the teaching evaluation methods based on the particularity of students "student + employees" double identity and the "campus + enterprise" double learning environment, which is also the inevitable choice to realize the high-quality enrollment expansion.

\section{THE THEORETICAL BASIS AND DEVELOPMENT MODEL OF BLENDED COURSE DEVELOPMENT}

Course design is the selection and planning of course content and resources according to certain curriculum concepts, and the optimal combination of various elements of curriculum implementation and evaluation.[5]

Vocational education takes study achievement output as the goal, develops the course based on the work-process systematization, with deepen the reform and supply of curriculum knowledge content. Making a specific, actionable, standardization of design and layout on structure of the curriculum system and contents, teaching methods and means, and curriculum evaluation to reflect the supporting degree of the curriculum system and content to the innovative talents training.

\subsection{The development of vocational education curriculum}

At present, the course development of vocational education is changing from the subject system to the action system, from indirect knowledge leading to direct knowledge leading, from teachers to students, from traditional learning to ubiquitous learning, from passive acceptance to active construction, and from knowledge memory to skill application.[6] The change of learning concept and learning mode under the background of the new era is bound to promote the innovative development of course design.

The purpose of the "work-process systematization" course is to promote the all-round development of people, with the employment-oriented and occupation-oriented concept.[7] The course development of vocational education should shift from the subject system curriculum structure based on subject knowledge systematization to the action system structure based on work-process systematization, and selects and arranges the content based on work-process systematization.

\section{2. "7Cs" SPOC course development model}

Conole $G$ etc. [8] puts forward an online-course development model consisting of vision, activity, synthesis and implementation through in-depth research and practice, which contains seven design processes (Figure 1).Buch B, etc. [9] think that the online-course development model should be a dynamic learning design model, which should not only pay attention to the interaction process, but also pay attention to the feedback process in the whole design. 


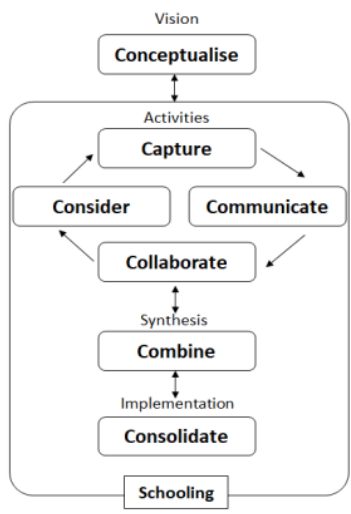

Figure 1. The development model for online course

In this model, the conceptualise which means vision aim to help teachers and designers understand students. In the blended course, it mainly includes teaching methods, core principles of the course, the nature of providing guidance and support, the types of content and activities, the ways of communication and collaboration, the reflection and interpretation of learning outcomes. The capture refers to the making of learning resources and the design of Activities. The communicate refers to the design of communication interaction, and the collaborate refers the design of corporate and group study. The consider refers to the design of reflection, including evaluation, feedback (interactive feedback), and the presentation of results. The combine refers to reflect to the design from different perspective with the combination of the above content, and make a description of course view, including providing guidance and support, the ways of interaction and cooperation mode, the reflection and display mode. Following consolidate (integration), the course realizes the course design under the real background, assesses their effectiveness, and carries out teaching practice in school education (Schooling)

\section{THE DEVELOPMENT PATH OF SPOC- BASED VOCATIONAL EDUCATION BLENDED COURSES}

The online-course development will not succeed just according to the form of a linear syllabus to guide the learning process purely. [10] Based on the research of Conole and Buch et al., the SPOC-based vocational education course development model is constructed with the dual-reconstruction of course content and structure based on the theory of work-process systematization curriculum development and outcomes-oriented, introducing the concept of iteration and emphasizing the importance of generative teaching resources (Figure 2).

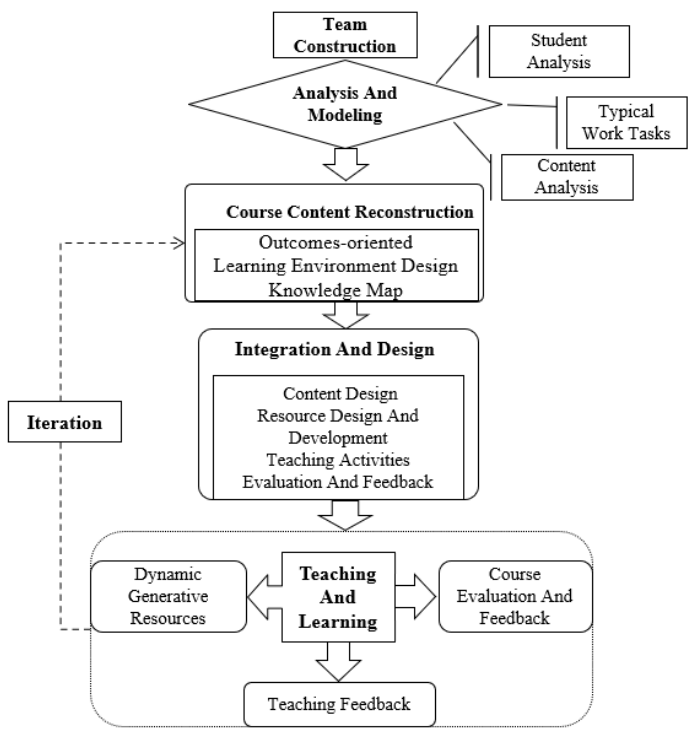

Figure 2. Blended course development process model based on work-process systematization

\subsection{Teaching innovation team}

The design and development of blended course not only includes course teaching design, but also includes the design of online and offline course modules, the design and development of learning resources, and the technical support of teaching activities. A high-quality online-course need to put the work together, including the lecturers and teaching team, teaching designers, technical support team, to complete the "double-reconstruction" of course content and structure, the optimization of teaching process, the development of learning resources, the analysis of learning data, and the supply of learning tool support, etc.

\subsection{Analysis and modeling}

The purpose of analysis and modeling is to determine the teaching content according to typical job analysis and position requirements, to determine the teaching objectives according to student analysis and teaching content analysis, and to construct the model of learning content and job demand to determine the reconstruction of course content. The student analysis is to build a learner cognitive model according to the starting ability level of students, learning needs and the cognitive characteristics of students in the era of mobile Internet.

The teaching content analysis is to determine the action field according to the students' learning results and the actual typical work tasks, to determine the learning field according to the action field, and to design the learning environment and determine the knowledge field, based on the concept of outcomes-oriented and the work-process systematization course development, which is to determine the teaching objectives. The model of learning content and 
vocational position ability achieves the precise docking between learning content and job position ability, clarifies the corresponding relationship between teaching content and students' expected ability, and guides the reconstruction, integration, design and implementation of course content.

\subsection{Course content reconstruction}

The selection and arrangement of course content are two core problems in course development [JIANG,2014]. With the transformation and upgrading of industrial structure and the transformation of traditional industry to service industry, the connotation of technical talents training in vocational colleges is constantly improving, and the demand for innovative technical talents is also increasing. For example, the equipment manufacturing industry's demand for technical talents is changing from production operant talents for a single position to technical talents for the whole process of production and multiple positions, which requires the talents to be able to adapt to different application scenarios to carry out product and production line installation, commissioning, operation and maintenance, service and other work.

The course development of vocational education should break the traditional single linear teaching content and methods according to the needs of industry change and transformation, integrate the "Four New" knowledge content to meet the new requirements of new position, vocational qualification certificate, " $\mathrm{X}$ " certificate standard and other to reconstruct the course content system.

The course content design should confirm which part of knowledge content and teaching stage are suitable for online learning and which are suitable for offline knowledge internalization, and how to connect them effectively to optimize teaching efficiency and achieve the "double-reconstruction" of the course.

Using visualized tools such as mind map and concept map to organize the "double-reconstruction" course content system and output the course knowledge map according to the model of learning content and vocational position ability.

And the knowledge map should integrate the position requirements according to the particularity of vocational education, and reflect the teaching methods, approaches and means of different knowledge contents in the blended teaching mode.

\subsection{The integration and design of course}

\subsubsection{The content design of blended course}

Blended teaching design should implement the concept of "student-centered", and adhere to the "outcomes-oriented" design to stimulate students' initiative and enthusiasm in learning. In online teaching, students' independent learning can be complete through the learning approaches of "taskdriven-watching video-- asking questions -- interactive discussion -- knowledge evaluation -- interactive evaluation". And the offline teaching can realize students knowledge internalization, knowledge application and skill generation through face-to-face teaching to improve students' sense of achievement.

In the course development, we should follow the Bloom's Classification of Educational Objectives to determine the teaching goals of different content, design teaching process, arrange teaching activities and teaching evaluation. The learning theory of behaviorism and others indicate that the factual learning content is suitable for the operation and practice teaching methods, the original rational and procedural content is suitable for intelligent teaching system, and the teaching of high-level thinking (personal significance construction) needs online-course and virtual experiment to support, and to promote learners to obtain new knowledge needs to use the network inquiry teaching mode.

The course should be designed systematization according to "double-reconstruction" of course content and the feature of core knowledge (such as which parts of knowledge need to study before class, and which need to focus on teaching), and arranged the online and offline learning content and goals reasonably to transform the course content into learning situation to complete the design of learning tasks.

\subsubsection{Resource design and development}

The learning content of vocational education is highly professional and technical, and emphasize students' handson ability and practical operation ability. For example, students who study electronic information technology not only learn computer programming and circuit board welding, but also learn how to assemble and operate the electronic products. The course design should select different teaching media according to different teaching contents. We should use the form of "visible and tangible" to convey relevant knowledge, let students master abstract concepts through concrete learning, so that students' direct experience and indirect experience have an organic connection. With the help of modern educational technology, we should make full use of animation, virtual simulation, VR, big data, artificial intelligence, 5G and other information technology to present learning content and develop learning resources to provide students with direct experience to the greatest extent.

\subsubsection{The teaching activities design}

The teaching activity is the main way to impart knowledge. Blended teaching needs to fully reflect the concept of "student-centered", and designs multi-interactive, strongly supportive teaching activities to stimulate students' 
learning enthusiasm and initiative, and also provides diversified learning support to meet the requirements of students' independent learning.

In blended teaching, the teaching activities include online teaching activities and offline teaching activities. The main forms of online teaching activities include watching course videos, carrying out seminars and activities, asking questions, mutual evaluation, and knowledge and skills evaluation, etc. Offline activities mainly refer to the faceto-face teaching supported by different technology, such as the explanation of difficult problems, personal achievements display, group collaboration task completion, content improvement and other interactive forms.

Based on the constructivism learning theory, the instructional design of blended courses should create a real learning environment and realizes the positive interaction between teachers and students by using rich media technology, group learning, online instruction, the discussion and interaction evaluation to improve the sense of social existence, the sense of cognitive and the sense of teaching. Students' learning initiative can be also improved and encouraged through interactive incentive mechanism

\subsubsection{Evaluation and feedback design}

The teaching evaluation reform. Adapting to the education evaluation requirements in the new times, we can evaluate students' learning status and outcomes from multiple perspectives such as overall, group and individual, with using the data from learning process and the platform based on the data statistics and analysis of interactive teaching system, such as students watch online video, assessment results, participate in discussion, etc. The theory of multiple intelligences advocates the concept of promoting development by evaluation, and pays attention to the diversity of evaluation subject and object, which can effectively examine the learning effect of students.

Timely feedback is needed. Students who received direct "detailed description + true/false" feedback are more motivated to learn and perform better in learning outcomes [11]. In the course design, it is necessary to design interactive feedback teaching activities with the help of modern information technology, so that teachers can adjust teaching pertinently. For example, teachers can use the Learning Apps to carry out real-time Q\&A and evaluation activities.

\subsection{The Implementation of teaching and learning}

According to the PDCA quality diagnosis and improvement model, course development is just one of processes of course teaching design which also includes application, diagnosis, improvement and so on, namely teaching implementation and feedback, course improvement. The process of teaching and learning mainly includes teaching implementation, course evaluation and feedback, teaching effect feedback and dynamic generative resource application.

Teaching and learning are the process of curriculum organization and implementation. The roles of course experts, education experts, teaching supervisors and others in the course construction team should be fully played in the teaching process. And we need to monitor and evaluate the implementation of blended teaching process, through in-class lectures, online learning monitor and so on. The advice and guidance of course content, teaching activity design, technology and means in the teaching process from timely evaluation and feedback are the basis of course iterative development. The teaching effect and students' learning effect are the key to evaluate the course construction. The supervision and analysis of the whole process of students' learning can obtain the learning effect of each project in the course, which can be used to adjust the knowledge representation and the teaching design.

Integrating the dynamic generative resources. Generative resources are procedural teaching resources which are derived from the students' learning and teachers' teaching in the teaching process, with important educational significance and value [12]. Generative resources come from teacher-student interaction, teaching activities, and students' works and practices, which can more truly reflect the problems existing in current teaching and learning. With the wide application of smart classroom, online teaching platform and mobile teaching terminal, generative resources generated in the teaching process can be acquired timely by teachers and students, and applied to continuous teaching and learning to promote the diagnosis and improvement of teaching, and enrich course resources.

\subsection{The iteration of course}

Course development is cyclical. The end of each teaching stage is the beginning of a new course development. In addition to the diversity and complexity of students, with the transformation of industries and technological innovation, the content of typical jobs is also changing. So, the course content needs to be re-analyzed, modeled, and reconstructed. In addition, the problems found in the course teaching implementation process, multi-level and multiangle feedback, students' learning process performance, etc., are also necessary for the course to carry out iterative development.

\section{CONCLUSION}

It is the actual demand that to carry out blended teaching reform to adapt to the "Internet + vocational education" new ecology and enhance the adaptability of vocational education. Based on the work-process systematization course development concept and outcomes-oriented study theory, with learning Conole and Buch's SPOC course development model and combining with the characteristics of vocational education as a type of education, the blended 
course development model is built by introducing the idea of "iteration" and strengthening the key role of generative teaching resources, which has directive significance to the reform and practice of developing the blended course.

\section{ACKNOWLEDGMENT}

This work was financially supported by the Guangdong teaching reform research and practice project (GDJG201904), and supported by Guangdong Youth Innovative Talents Project (2020WQNCX205), and supported by teaching reform research and practice project of Dongguan Polytechnic (JGZX202018).

\section{REFERENCES}

[1] Yu Shengquan, LU Qiuli, Chen Shengjian. "Blended teaching under network environment- a new teaching mode", China University Teaching, pp. 50-56, October 2015.

[2] Liao Hongjian, ZHANG Qianwei."Construction and application of mixed teaching readiness index in colleges and universities", Research of audio-visual education, Volume 40, Issue 3, pp. 59-67, 2019.

[3] Circular of the ministry of education on the issuance of education informatization 2.0 action plan

http://www.moe.gov.cn/srcsite/A16/s3342/201804/t201 80425_334188.html

[4] Wang Zhiming. "From fit to lead: new driving force of higher vocational education reform and development in transition period", Guangming Daily Press, pp. 103108, 2017.
[5] Yin Rui. "Content analysis of design and development characteristics of hundreds of foreign massive open online courses: Curriculum Perspective", Research on audio-visual education, December 2015.

[6] Yan Zhiyong, Wu Quanquan, Xu Chun. “The evolution and development trend of vocational education course model", Vocational Education Forum, pp. 48-55, January 2019.

[7] Jiang Dayuan. "Work-process systematization: the development of modern vocational education course with Chinese characteristics", Journal of Shunde Polytechnic, Volume 12, Issue 3, pp. 1-11+27, 2014.

[8] Conole G. Update on the 7Cs of learning design framework [Internet]. e4innovation.com. [cited 2016 Jan 1]. Available from: http://e4innovation.com/?p=616

[9] Buch B, Christiansen R B, Hansen D, et al. "Using the $7 \mathrm{cs}$ framework for designing MOOCs in blended contexts--new perspectives and ideas", Universal Journal of Educational Research, 2018.

[10] Basu K. "Faculty groups consider how to respond to MOOCs", Inside Higher Ed, pp. 10-13, 2013

[11] Fabienn M. et al. "Effects of feedback on a computer-based assessment for learning". Computers \& Education, Volume 58, Issue 1, pp. 263-272,2012.

[12] Jiao Jianli. The generative resources in the classroom teaching [EB/OL].

https://www.jiaojianli.com/7333.html.2018.08 